\title{
Postservice lower limb amputation in Scottish military veterans
}

\author{
Beverly P Bergman 지 , DF Mackay, JP Pell
}

Institute of Health and Wellbeing, University of Glasgow, Glasgow, UK

\section{Correspondence to}

Dr Beverly P Bergman, Institute of Health and Wellbeing, University of Glasgow, Glasgow G12 8RZ, UK; Beverly. bergman@glasgow.ac.uk

Received 16 November 2020 Revised 7 December 2020 Accepted 11 December 2020

Published Online First 25 January 2021
Check for updates

(C) Author(s) (or their employer(s)) 2022. No commercial re-use. See rights and permissions. Published by BMJ.

To cite: Bergman BP,

Mackay DF, Pell JP.

BMJ Mil Health

2022:168:25-28.

\section{ABSTRACT}

Introduction Recent attention has focused on veterans who have lost limbs in conflict, but the number of UK veterans who lose limbs to disease is unknown. We used data from the Trends in Scottish Veterans' Health study to explore postservice lower limb amputation.

Methods We carried out a retrospective cohort study of 78000 veterans and 253000 non-veterans born between 1945 and 1995, matched for age, sex and area of residence. We used survival analysis to examine the risk of amputation in veterans compared with non-veterans, and explored associations with antecedent disease.

Results We found no difference between veterans and non-veterans in the risk of lower limb amputation, which was recorded in 145 (0.19\%) veterans and 464 (0.18\%) non-veterans (Cox proportional hazard ratio (HR) 1.00, $95 \% \mathrm{Cls} 0.82$ to $1.20, p=0.961)$. Peripheral arterial disease was recorded in two-thirds of both veteran and non-veteran amputees, and type 2 diabetes in $41 \%$ of veterans and $33 \%$ of non-veterans, with a dual diagnosis in $32 \%$ of veterans and $26 \%$ of non-veterans. Trauma was an infrequent cause of amputation.

Conclusions Although in later life veterans are no more likely to lose a limb to disease than non-veterans, the number so affected greatly outweighs those who have lost limbs in conflict. The high public profile of conflictrelated limb loss risks eclipsing the needs of veterans with disease-related loss. Support for ageing veterans who have lost limbs due to disease will require planning with the same care as that afforded to the victims of conflict if inequalities are to be avoided.

\section{INTRODUCTION}

Amputation of a limb or part thereof is one of the most visible reminders of the physical consequences of battle injury. Between 2001 and 2019, 301 UK service personnel underwent an amputation as a result of injuries sustained on operations in Afghanistan, with a further 32 as a result of service in Iraq between 2003 and 2019. An additional 142 service personnel underwent amputation for conditions sustained in other locations between 2014 and 2019. While some of these amputations involved digits only, over 110 sustained multiple limb amputations, mainly from Afghanistan. Limb amputation does not automatically result in medical discharge from service; individuals who regain sufficient medical fitness may continue to serve if they so wish, subject to assessment by a Medical Board. However, over 250 personnel who have sustained amputations in recent conflicts have been medically discharged and become veterans. ${ }^{1}$
Key messages

In the long term, the number of veterans who undergo lower limb amputation for disease far exceeds the number who lose limbs in conflict.

- Military veterans are no more likely to experience lower limb amputation after leaving service than people who have never served.

- The most common causes recorded for lower limb loss, in both veterans and non-veterans, are peripheral arterial disease (PAD) followed by type 2 diabetes, accounting for a total of $66 \%$ and over $33 \%$ of cases, respectively.

- Smoking-related diseases (ischaemic heart disease, lung cancer and PAD) are the the most common causes of death in amputees, irrespective of military service.

- Veterans who lose limbs to disease should be afforded the same level of support as combatrelated amputees.

Combat-associated trauma is not the only cause of limb amputation which military personnel and veterans may face. ${ }^{2}$ Younger people may face amputation as a consequence of civilian trauma, such as road traffic accidents, while both diabetes and peripheral arterial disease (PAD) are major causes of limb loss in later life. ${ }^{3}$ A study of US veterans showed that 63\% of amputations between 1989 and 1998 were for diabetes and 24\% for peripheral vascular disease, with overall age-specific rates for veterans exceeding those in the general US population. ${ }^{45}$ We have shown that Scottish veterans are at increased risk of PAD compared with the wider population, ${ }^{6}$ but we had no information on whether this was associated with an increased incidence of limb loss.

Amputation carries substantial costs, both economically, in terms of the costs associated with surgery, rehabilitation and prostheses, and personally, with respect to loss of independence, altered body image, impact on the family and perhaps changes in employability. ${ }^{3}$ It also has important implications for care needs, especially in older people, ${ }^{7-9}$ but risks and antecedent causes of postservice amputations in UK veterans are unknown. We used data from the Scottish Veterans Health Study 5-year follow-up, Trends in Scottish Veterans' Health, to examine lower limb amputations in veterans in comparison with age, sex and geographically matched people with no record of service. 


\section{METHODS}

Trends in Scottish Veterans' Health is a retrospective cohort study of all 78385 military veterans resident in Scotland who were born between 1 January 1945 and 31 December 1995, and a comparison group of 252637 individuals with no record of service matched 3:1 for age, sex and postcode sector of residence (mean population of 5000). Veterans were eligible for inclusion if they were registered with National Health Service (NHS) Scotland both preservice and postservice. The study follows on from the Scottish Veterans Health Study, using similar methodology, which is fully described elsewhere. ${ }^{10}$ Demographic data obtained from electronic NHS registration records were linked at an individual level to routine hospital admissions data (Scottish Morbidity Record SMR01), the Scottish Diabetes Register, and death certificates to provide information on all recorded lower limb amputations and first recorded diagnosis of diabetes (including type), PAD, trauma and all-cause death. Anonymised data were also obtained from Blesma, The Limbless Veterans charity, on the lower limb amputees of whom they have record in Scotland. Although membership of Blesma is voluntary, it is likely to be reasonably complete with respect to military operational casualties. Dates of entering and leaving the service, for veterans, were obtained from the Scottish NHS registration record. The maximum period of follow-up was from 1 January 1981 (or date of leaving the Armed Forces, for veterans, if later) to 31 December 2017. Data on the gender balance of the Armed Forces were taken from published Ministry of Defence statistics. ${ }^{11}$ Individual-level prescribing data were obtained from the NHS Prescribing Information System for a limited range of drugs including nicotine replacement therapy (NRT). As we had no data on lifestyle risk factors, we used NRT prescribing as a proxy measure for smoking. ${ }^{10}$

\section{Socioeconomic status (SES)}

A measure of SES is provided by the Scottish Index of Multiple Deprivation (SIMD), which is based on 6505 datazones, derived from postcode of residence, each having a mean population of 800 . Deprivation status is calculated from information on income, employment, health, education (including skills and training), housing, crime and access to services. The SIMD has been used to derive quintiles of SES for the Scottish population, ranging from 1 (most deprived) to 5 (least deprived). ${ }^{12}$ The cohort participants were categorised according to these quintiles using postcode of residence.

\section{Statistical methods}

For the purposes of the study, lower limb amputation was defined as any occurrence of the OPCS Classification of Interventions and Procedures V.4 (OPCS-4) ${ }^{13}{ }^{14}$ codes X01, X07, X08, X081, X09, X095, X11 or X12, including subcodes where appropriate, or OPCS-3 codes $870-875$ or $862-864$, and a diagnosis of diabetes was defined as International Statistical Classification of Diseases and Related Health Problems, 10th Revision (ICD-10), E10-E14, or International Statistical Classification of Diseases and Related Health Problems, Revision 9 (ICD-9) 250 at any position in the NHS SMR01 record, or an entry in the Scottish Diabetes Register. For Scottish Diabetes Register entries, we restricted the analysis to type 2 diabetes. For SMR01 records, where type of diabetes was not recorded, we restricted the analysis to cases first diagnosed at age 30 years or later to maximise the likelihood of capturing type 2 disease. PAD was defined as ICD-10 I73-I79 or I702, or ICD-9 443.9 or 440.2. Trauma was defined as ICD-10 S00-S99, T00-T32 or ICD-9 E850-E858,
E860-E869 or 960-989.4, and road traffic accident was defined as ICD-10 V00-V99 or ICD-9 E809-E819 or E820-E825. ${ }^{15}$

Cox proportional hazard models ${ }^{16}$ were used to examine the association between veteran status and cumulative risk of amputation, overall and in association with specific antecedent conditions, using age as the time-dependent variable, age at first record of amputation as the failure time and death (if no amputation) as the censor time. A landmark analysis was performed using age 40 years as the starting point for PAD. We also examined comorbidity with mental health diagnoses where this was recorded on the inpatient or death record and, in particular, with severe stress or post-traumatic stress disorder (PTSD) (ICD-10 F43 or ICD-9 308 or 309). Hazard ratios and p values were calculated and the a priori rejection level was set at 0.05 . Proportionality was tested using methodology based on Schoenfeld residuals. ${ }^{17}$ The models were run univariably and then repeated, adjusting for the potential confounding effect of SES. The analyses were repeated, stratifying by 5 -year bands of birth year, to examine birth cohort effects, and stratifying by length of service. All analyses were performed using Stata V.16.

\section{RESULTS}

After data cleansing to remove incomplete and invalid records, 78157 (99.7\%) veterans and 252637 (100.0\%) non-veterans were included in the analysis. The dataset included 7573 $(9.7 \%)$ women veterans, reflecting the gender balance of the Armed Forces, and 28983 (11.5\%) non-veteran women. Health outcome data were available for a total of 10643252 personyears of follow-up.

During the period of follow-up, $145(0.19 \%)$ veterans and $464(0.18 \%)$ non-veterans underwent a lower limb amputation. The difference was not statistically significant (Cox proportional hazard ratio (HR) $1.00,95 \%$ CI 0.82 to $1.20, \mathrm{p}=0.961$ ) (Figure 1). The median age at the first record of amputation was 55.6 years (IQR 47.2-61.5) for veterans and 54.0 years (IQR 44.2-61.3) for non-veterans. Less than 5\% (exact numbers suppressed) of those who had undergone lower limb amputation were women, with no significant difference between veteran and non-veteran women.

The most common association with lower limb amputation was PAD, which was recorded in 95 (65.5\%) amputations in veterans and $310(66.8 \%)$ in non-veterans. Although PAD was more common overall in veterans than non-veterans $(1.34 \%$

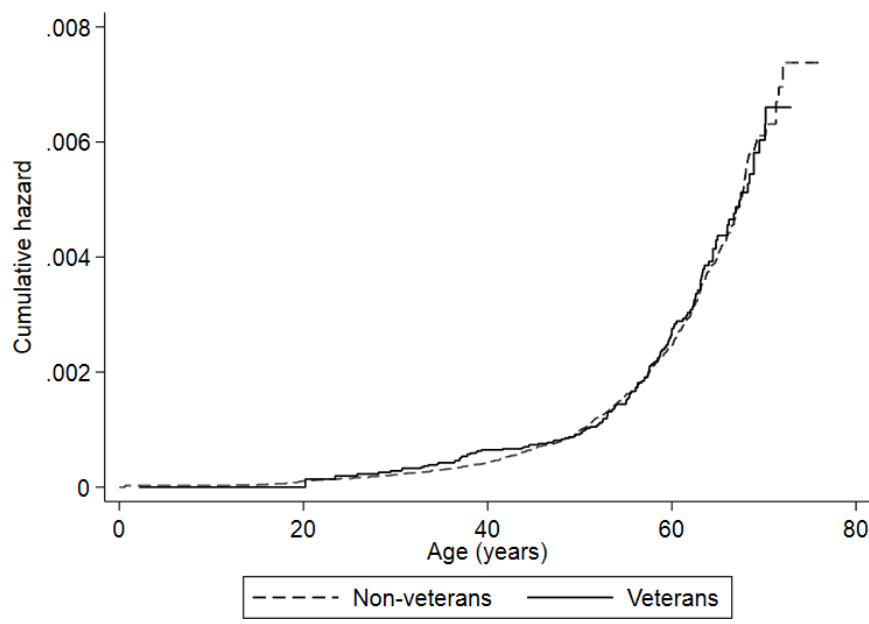

Figure 1 Nelson-Aalen cumulative hazard plot of risk of lower limb amputation in veterans compared with non-veterans. 


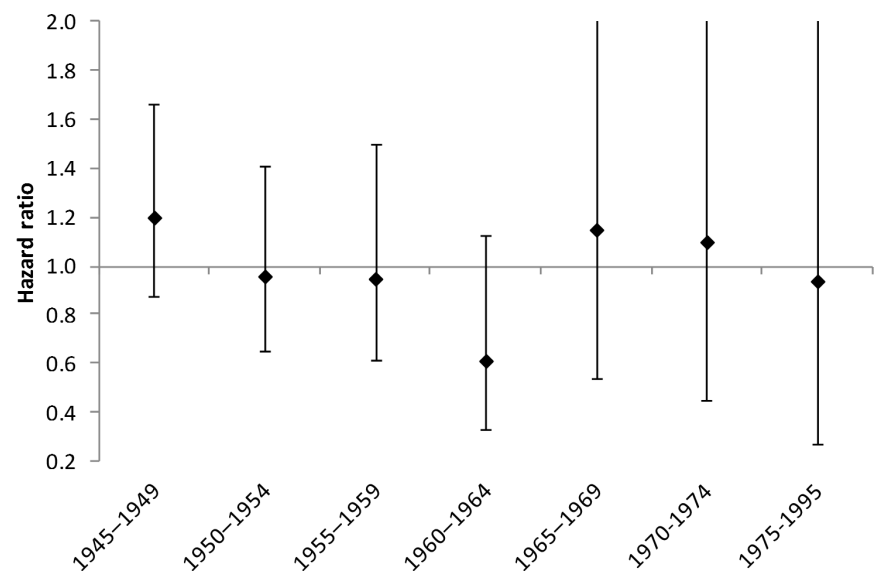

Figure 2 HRs for lower limb amputation by birth cohort, veterans versus non-veterans. Error bars represent $95 \% \mathrm{Cls}$.

vs $0.98 \%$, HR $1.29,95 \%$ CI 1.20 to $1.39, \mathrm{p}<0.001$ ), the risk of progressing to limb loss in veterans was lower than in nonveterans, with $9.0 \%$ of cases leading to amputation in veterans compared with $12.6 \%$ in non-veterans. The reduction in risk was statistically significant (HR $0.66,95 \%$ CI 0.52 to 0.84 , $\mathrm{p}=0.001)$. The second most common associated diagnosis was type 2 diabetes, diagnosed in 61 (42.1\%) of veteran amputations and 154 (33.1\%) in non-veterans. The difference in risk was not statistically significant (HR 1.03 , 95\% CI 0.77 to 1.41 , $\mathrm{p}=0.807)$. There was a substantial overlap; 47 veterans $(32.4 \%$ of all lower limb amputees) and 123 (26.5\%) non-veterans had a dual diagnosis of PAD and type 2 diabetes. Again, the difference in risk was non-significant (HR $0.79,95 \%$ CI 0.56 to 1.11 , $\mathrm{p}=0.174$ ). Trauma (including road traffic accidents) was a very small contributor, accounting for just over $5 \%$ of amputations in veterans and under $5 \%$ in non-veterans (exact numbers suppressed); the differences were not statistically significant. Neither birth cohort (Figure 2) nor length of service (Figure 3) influenced risk of lower limb amputation, apart from a small peak at 10-12 years of service. Being an early service leaver did not increase the risk of postservice amputation.

By the end of follow-up, 68 (46.9\%) veterans who had undergone lower limb amputation had died, as had 211 (45.5\%) nonveterans. The HR for all-cause mortality was 0.98 (95\% CI 0.96 to $1.01, p=0.288)$. The most common cause of death, for both veterans and non-veterans, was acute myocardial infarction or ischaemic heart disease, followed by lung cancer and PAD.

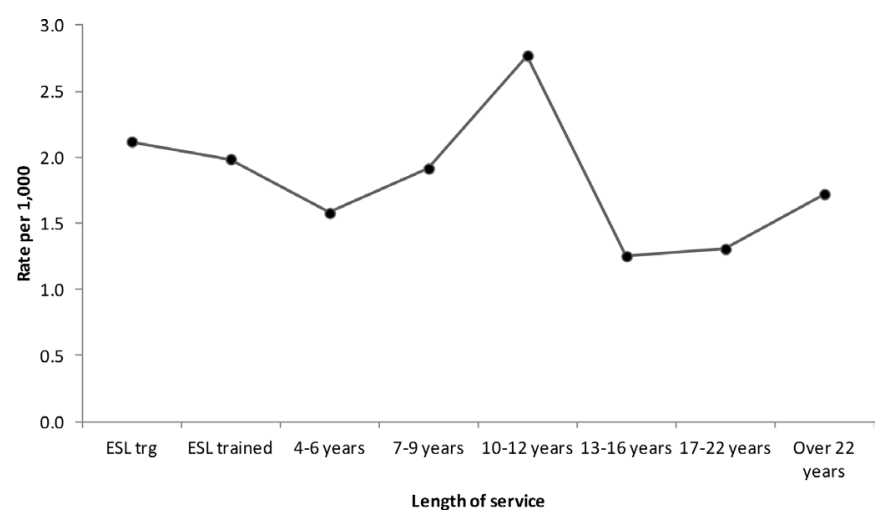

Figure 3 Lower limb amputation in veterans, crude rate by length of service. Categories represent common terms of military engagement. ESL: Early Service Leaver
Blesma data showed 38 veterans living in Scotland with service-related lower limb amputations who would have met the age criteria for our study. Of these, 32 were aged under 50 years and so were likely to have been associated with recent conflicts, while only 6 were older. Of the veterans registered with Blesma who had disease-related lower limb amputations (all ages), $67.7 \%$ were self-declared as due to PAD and $29.0 \%$ to diabetes.

We used NRT as a proxy for smoking prevalence; veterans were significantly more likely than non-veterans to have received a prescription for NRT; $8812(11.2 \%)$ veterans were prescribed NRT, compared with 24775 (9.8\%) non-veterans (OR 1.15, 95\% CI 1.12 to $1.17, \mathrm{p}<0.001)$. However, NRT prescription rates for amputees did not differ between veterans and nonveterans, $17.2 \%$ for both.

There was an increased risk of amputation in veterans with a record of severe stress or PTSD (4.1\% of veteran amputees compared with $2.8 \%$ of non-veterans) and with mood disorder (13.1\% of veteran amputees compared with 9.5\% of nonveterans), although neither achieved statistical significance owing to small numbers (OR $1.48,95 \%$ CI 0.57 to $3.81, \mathrm{p}=0.419$ for stress/PTSD and OR 1.38, 95\% CI 0.83 to $2.29, \mathrm{p}=0.211$ for mood disorder). There was no difference for anxiety $(6.9 \%$ vs $6.5 \%)$.

\section{DISCUSSION}

We have shown that in long-term follow-up (up to 57 years postservice), the risk of postservice lower limb amputation in veterans does not differ from non-veterans. Two-thirds of cases were associated with PAD in both veterans and non-veterans, while there was an association with type 2 diabetes in over $40 \%$ of veteran amputees and one-third of non-veterans. PAD in patients with type 2 diabetes was common. Perhaps surprisingly, trauma was a rare cause of postservice amputation; although this cohort overlaps the period of intense military operations in Iraq and Afghanistan, it appears that few of the in-service amputees who became veterans and settled in Scotland have needed to undergo further amputation. Nor do veterans appear to be at increased risk of traumatic injury leading to amputation, notwithstanding the well-documented association between deployment and risk of road traffic accident, ${ }^{18}$ and between military service and risky driving. ${ }^{19} 20$

Although the number of veterans who settle in Scotland having sustained an in-service amputation is not formally recorded, a figure of approximately $10 \%$ of the UK-wide figures is widely used for planning purposes in various contexts since approximately $10 \%$ of the Armed Forces are recruited from Scotland. ${ }^{21}$ Therefore, it is likely that there are around $30-40$ veteran amputees from recent conflicts living in Scotland. This estimate is supported by our analysis of the Blesma data. Prior to the start of hostilities in Iraq and Afghanistan, amputation as a consequence of military service would have been uncommon. Therefore, our finding that 145 veterans in Scotland had undergone postservice lower limb amputation, mostly due to disease, demonstrates that diabetes and peripheral vascular disease account for more limb loss in veterans than conflict.

Smoking is widely recognised as a risk factor for lower limb loss. Studies in the USA have shown that veterans are more likely to smoke than non-veterans, ${ }^{22}$ and UK studies in the $1960 \mathrm{~s}$ and 1970s, when the older veterans in our study were serving, showed that serving soldiers were more likely to smoke, and to smoke more heavily, than civilians. ${ }^{23} 24$ Therefore, it might be anticipated that amputation for vascular reasons is more common. We have shown that PAD is more common in veterans, 
both in our earlier study ${ }^{6}$ and confirmed in this follow-up, but that paradoxically fewer amputations take place in veterans with PAD than non-veterans. We suggest that this may be due to earlier presentation, and hence greater likelihood of limb-saving treatment, as veterans may be less likely to ignore the symptoms of claudication than non-veterans.

The strength of this study is that we had access to follow-up data on over 330000 people, including over 78000 veterans, over a period of up to 37 years. The data were drawn from Scottish computerised healthcare records and so were likely to be complete with respect to surgical procedures carried out in NHS facilities. The use of record linkage to analyse individual-level data directly derived from health records allowed a robust cohort study design to be employed. It was possible to do subgroup analyses by sex, birth cohort and length of service, contributing to the understanding of factors influencing veterans' health.

Some loss to follow-up of subjects is likely to have occurred due to migration away from Scotland. Such losses could not be quantified, and the assumption has been made that there was no systematic difference in this respect between veterans and non-veterans. No data were available for smoking rates so we have inferred likelihood of smoking from other studies, and from NRT prescribing data. We had no data on the Service (Royal Navy, Army and Royal Air Force) to which a veteran belonged. Veterans with Reserve service only could not be identified from NHS records and were therefore included among the non-veterans; this would have had the effect of reducing any observed differences between veterans and non-veterans, although the numbers involved are likely to be too small to have an important impact on our findings.

\section{CONCLUSIONS}

Lower limb amputation brings care needs, especially as amputees age when mobility and ability to manage a prosthesis become impaired. Recent attention has focused on the long-term needs of the amputee veterans of recent conflicts. We have shown that although in later life veterans are no more likely to lose a limb to disease than are people who have never served, the number of veterans so affected will greatly outweigh those who have lost limbs in conflict. The burden on care provision for ageing veterans is considerable and will require planning with the same care as that afforded to the victims of conflict, who generally benefit from a higher profile and greater perceived public support, if major inequalities within the veteran community are to be avoided. This highlights an important aspect of the Armed Forces Covenant; notwithstanding the right to priority treatment for those injured in service, there should be no difference in the provision of long-term support (actual or perceived), either in comparison with the civilian community or within the veteran community itself.

Acknowledgements We thank the staff of the NHS Central Registry for extracting the dataset, the eDRIS Team (Public Health Scotland) for their involvement in obtaining approvals, provisioning and linking data and the use of the secure analytical platform within the National Safe Haven, and Blesma, The Limbless Veterans for provision of anonymised data on their clients in Scotland.

Contributors BPB conceived the idea and designed the study, with advice from JPP and DFM. BPB carried out the data analysis, which was overseen by DFM, and interpreted the findings. BPB wrote the first draft of the report, which was critically reviewed and edited by all authors. All authors approved the final article. BPB revised the article following review, which was approved by all authors.

Funding This study was supported by a Forces in Mind Trust grant (FiMT17/1101UG).
Competing interests BPB is a military veteran and Honorary Civilian Consultant Advisor (Army) in Veterans' Health and Epidemiology. Neither the Army nor the Ministry of Defence had any input to this paper, and the views and opinions expressed are solely those of the authors.

\section{Patient consent for publication Not required.}

Ethics approval The data extract was pseudo-anonymised and approval for the study was granted by the Public Benefit and Privacy Panel of the Information Services Division of NHS Scotland. Use of anonymised extracts of Scottish routine data for health research is covered by generic NHS ethics approval (East of Scotland Research Ethics Committee; reference 16/ES/0112). As this was a secondary data study, individual consent was not required.

Provenance and peer review Not commissioned; externally peer reviewed.

Data availability statement No data are available. The study remains in progress and the data are not currently available for sharing.

\section{ORCID iD}

Beverly P Bergman http://orcid.org/0000-0003-4596-3399

\section{REFERENCES}

1 Defence Statistics (Health). Amputation statistics Abbey wood: Ministry of Defence; 2019

2 Caddick N, Cullen $\mathrm{H}$, Clarke $\mathrm{A}$, et al. Ageing, limb-loss and military veterans: a systematic review of the literature. Ageing Soc 2019;39:1582-610.

3 Moxey PW, Hofman D, Hinchliffe RJ, et al. Epidemiological study of lower limb amputation in England between 2003 and 2008. Br J Surg 2010;97:1348-53.

4 Mayfield JA, Reiber GE, Maynard C, et al. Trends in lower limb amputation in the Veterans Health Administration, 1989-1998. J Rehabil Res Dev 2000;37:23.

5 Mayfield JA, Reiber GE, Maynard C, et al. The epidemiology of lower-extremity disease in veterans with diabetes. Diabetes Care 2004;27 Suppl 2:B39-44.

6 Bergman BP, Mackay DF, Pell JP. Peripheral arterial disease in Scottish military veterans: a retrospective cohort study of 57000 veterans and 173000 matched nonveterans. J Public Health 2019:41:e9-15.

7 Coletta EM. Care of the elderly patient with lower extremity amputation. J Am Board Fam Pract 2000;13:23-34.

8 Sigford BJ. Paradigm shift for VA amputation care. J Rehabil Res Dev 2010;47:xv-xix.

9 Wilson G, McGill G, Osborne A, et al. Housing needs of ageing veterans who have experienced limb loss. Int J Environ Res Public Health 2020;17:1791.

10 Bergman BP, Mackay DF, Pell JP. Acute myocardial infarction in Scottish military veterans: a retrospective cohort study of 57,000 veterans and 173,000 matched nonveterans. Am J Epidemiol 2014;179:1434-41.

11 Defence Statistics (Tri Service). UK Armed Fforces Quarterly Personnel Report. London; 2013.

12 Scottish Government. Scottish Index of Multiple Deprivation 2012. Edinburgh; 2012.

13 NHS Digital. DCB0084: OPCS classification of interventions and procedures, 2020. Available: https://digital.nhs.uk/data-and-information/information-standards/ information-standards-and-data-collections-including-extractions/publications-andnotifications/standards-and-collections/dcb0084-opcs-classification-of-interventionsand-procedures

14 NHS Digital. OPCS classification of interventions and procedures version 4.9. London TSO (The Stationery Office); 2020.

15 World Health Organisation. International Statistical Classification of Diseases and related health problems 10th revision Geneva: World Health Oorganisation, 2010. Available: https://icd.who.int/browse10/2010/en

16 Cox DR. Regression models and life-tables. J R Stat Soc Series B Stat Methodol 1972;34:187-202.

17 Grambsch PM, Therneau TM. Proportional hazards tests and diagnostics based on weighted residuals. Biometrika 1994;81:515-26.

18 Lincoln AE, Hooper TI, Kang HK, et al. Motor vehicle fatalities among Gulf War era veterans: characteristics, mechanisms, and circumstances. Traffic Inj Prev 2006;7:31-7.

19 Fear NT, Iversen AC, Chatterjee A, et al. Risky driving among regular armed forces personnel from the United Kingdom. Am J Prev Med 2008;35:230-6.

20 Sheriff RJS, Forbes HJ, Wessely SC, et al. Risky driving among UK regular armed forces personnel: changes over time. BMJ Open 2015;5:e008434.

21 Ministry of Defence. Freedom of information response FOI-13-02-212-121523-005 dated 23 February 2012; 2012

22 Brown DW. Smoking prevalence among US veterans. J Gen Intern Med 2010;25:147-9.

23 Crowdy JP, Lewthwaite CJ, Sowden RR. Smoking: the changing habits of male adolescents a comparison of three generations of young soldiers. J R Army Med Corps 1975;121:126-31.

24 Lewthwaite CJ, Graham JT. The smoking habits of young soldiers. J R Army Med Corps 1992;138:67-71. 